\title{
Comparison of the photoactivities of two commercial titanium dioxide powders in the degradation of 1,4-dioxane
}

\author{
M. Mehrvar, ${ }^{1, \dagger}$ W. A. Anderson, ${ }^{2}$ and M. Moo-Young ${ }^{2}$ \\ ${ }^{1}$ Department of Chemistry, Biology and Chemical Engineering, Ryerson University, Toronto, \\ Ontario, Canada M5B 2K3 \\ ${ }^{2}$ Department of Chemical Engineering, University of Waterloo, Waterloo, Ontario, Canada N2L 3G1
}

\begin{abstract}
Two different commercial photocatalysts, Degussa P25 and Hombikat UV 100, were used to degrade 1,4-dioxane photocatalytically in an annular slurry photoreactor. The optimum photocatalyst loading for Degussa P25 was found to be $1.5 \mathrm{~g} \mathrm{~L}^{-1}$ while for Hombikat UV 100 was between $3.0-4.0 \mathrm{~g} \mathrm{~L}^{-1}$. The photoactivity of Degussa P25 is higher than that of Hombikat at lower photocatalyst loadings whereas it is lower at higher photocatalyst loadings. This was found both experimentally and also by mathematical modeling of the radiation within the photoreactor zone. The photoactivity of UV 100 titanium dioxide was found to be twice that of Degussa P25 at optimum loadings.
\end{abstract}

\section{INTRODUCTION}

Currently, n-type titanium dioxide is the most commonly used photocatalyst in photocatalytic treatment of water and wastewater because of its superior photoactivity and low toxicity [1]. Although there are many different sources of titanium dioxide, Degussa $\mathrm{P} 25 \mathrm{TiO}_{2}$ has effectively become a research standard because of its well-defined nature. Also, Degussa P25 $\mathrm{TiO}_{2}$ has a substantially higher photocatalytic activity than most of the other available samples of $\mathrm{TiO}_{2}$ [1]. In this work, photocatalytic destruction of 1,4-dioxane using two commercially available titanium dioxide photocatalysts, Degussa P25 and Hombikat UV 100, has been studied to compare their photoactivities as a function of concentration in a slurry photoreactor. It has been previously shown that 1,4-dioxane is photocatalytically degradable, and kinetic studies are reported thoroughly in the literature [2-5].

\section{MATERIALS AND METHODS}

The slurry photoreactor was made annular by two borosilicate glass tubes. The outer glass cylinder had $105 \mathrm{~mm}$ internal diameter (ID) and the internal glass cylinder had $48 \mathrm{~mm}$ outer diameter and $44 \mathrm{~mm}$ inner diameter. The details and schematic diagram of the experimental set-up has already been described in two different publications $[4,5]$.

The temperature throughout the experiments was kept at $25 \pm 2{ }^{\circ} \mathrm{C}$ with a circulating water bath. UV light was provided by a UV lamp inside and six UV lamps around the photoreactor. These tubular $20 \mathrm{~W}$ lowpressure mercury-vapour fluorescent lamps emitting

†E-mail: mmehrvar@ryerson.ca long-wave ultraviolet radiation were provided by Philips ('TL' 20W/09N). The UV lamps were $61 \mathrm{~cm}$ in length and $38 \mathrm{~mm}$ in diameter. They emit highly concentrated radiation between 320 and $390 \mathrm{~nm}$ with maximum peak at $350 \mathrm{~nm}$.

Before starting each run, the water was aerated to a saturation level using air. The liquid in the reservoir was magnetically stirred to increase the mass transfer between the headspace and the liquid as well as to provide a homogeneous system.

Prior to testing, the liquid samples were centrifuged by Centrifuge IEC Centra-HN (International Equipment Company) at about $4500 \mathrm{rpm}$ to remove $\mathrm{TiO}_{2}$. The samples were then analyzed using a Hewlett Packard (Avondale, PA) 5890 Series II Gas Chromatograph equipped with a flame ionization detector. The column was an RTX-502.2 fused Silica megabore column with $30 \mathrm{~m} \times$ $0.53 \mathrm{~mm}$ ID and $3.0 \mu \mathrm{m}$ film thickness (Chromatographic Specialists Inc.). An HP ultraviolet/visible spectrophotometer was used to measure the absorbance and transmittance of the solutions with suspended titanium dioxide particles in a $1 \mathrm{~cm}$ quartz cell.

Filtered deionized water was used in the experiments. HPLC grade 1,4-dioxane was purchased from Sigma Chemical Company. Two different types of photocatalysts were used in this study, titanium dioxide P25 (Degussa Corporation, Akron $\mathrm{OH}$ ) and Hombikat UV 100 (Sachtleben Chemie GmbH, Duisburg, Germany). The properties and supplemental information of these two photocatalysts are summarized in Table 1 .

In these experiments, 7 liters of filtered deionized water was fed to the photoreactor. A certain amount of titanium dioxide was then added to the photoreactor. The slurry was then recirculated for 15 minutes. During this period, all UV lights were turned on in 
Table 1. Physical properties and supplemental information for two different photocatalysts. This information was provided by the suppliers.

\begin{tabular}{lll}
\hline PROPERTIES & DEGUSSA P25 TITANIUM DIOXIDE & HOMBIKAT UV 100 TITANIUM DIOXIDE \\
\hline $\mathrm{TiO}_{2}$ Content & $>99.5 \%$ & $>99 \%$ \\
\hline Composition & $70 \%$ Anatase & $100 \%$ Anatase \\
\hline Primary Particle Size & $21 \mathrm{~nm}$ & \\
\hline Specific Surface Area & $36-65 \mathrm{~m}^{2} \mathrm{~g}^{-1}$ & $<10 \mathrm{~nm}$ \\
\hline Density & $3.8 \mathrm{~g} \mathrm{~cm}^{-3}$ & $>250 \mathrm{~m}^{2} \mathrm{~g}^{-1}$ \\
\hline Solubility in Water & Insoluble & $3.9 \mathrm{~g} \mathrm{~cm}^{-3}$ \\
\hline
\end{tabular}

order to eliminate any traces of background organics either left from the previous runs or present in the filtered deionized water. Then the lights were turned off and a certain amount of 1,4-dioxane stock solution was injected into the system to achieve the desired initial concentration. The slurry was then allowed to circulate while the lights were off for another 15 minutes. The UV lights were turned on and the photocatalytic reactions started.

\section{RESULTS AND DISCUSSION}

3.1. Dark reactions and photolysis. To prove photocatalysis was the main source of organic disappearance, dark and photolytic control experiments were carried out. In the dark reaction experiments no $\mathrm{TiO}_{2}$ was used and the UV lights were off during the runs. In the photolytic experiment, the UV lights were turned on, but no titanium dioxide was present. Both the dark reaction and photolysis were found to be insignificant ( $<10 \%$ decrease).

\subsection{Optimization of catalyst loading.}

\subsubsection{Degussa P25 Titanium Dioxide}

To optimize Degussa P25 titanium dioxide, the photoreactor was loaded with different slurry loadings. Figure 1 depicts the time-concentration plot of photocatalytic degradation of 1,4-dioxane using Degussa P25 $\mathrm{TiO}_{2}$ in the slurry photoreactor. In these experiments, all conditions remained constant except the $\mathrm{TiO}_{2}$ loadings. The initial concentration of 1,4-dioxane for all experimental runs was $27.8 \mathrm{mg} \mathrm{L}^{-1}(316 \mu \mathrm{M})$. Although all degradation curves are close to each other as depicted in Figure 1 , it can be demonstrated that an optimum catalyst loading exists. This can be done either by estimating initial rates or by finding reaction rate constants. The details are discussed in Section 3 3.2 3.2.3.

\subsubsection{Hombikat UV 100 Titanium Dioxide}

Another set of experiments was carried out using a relatively new titanium dioxide called Hombikat UV 100. For the ease of comparison, the initial concentration

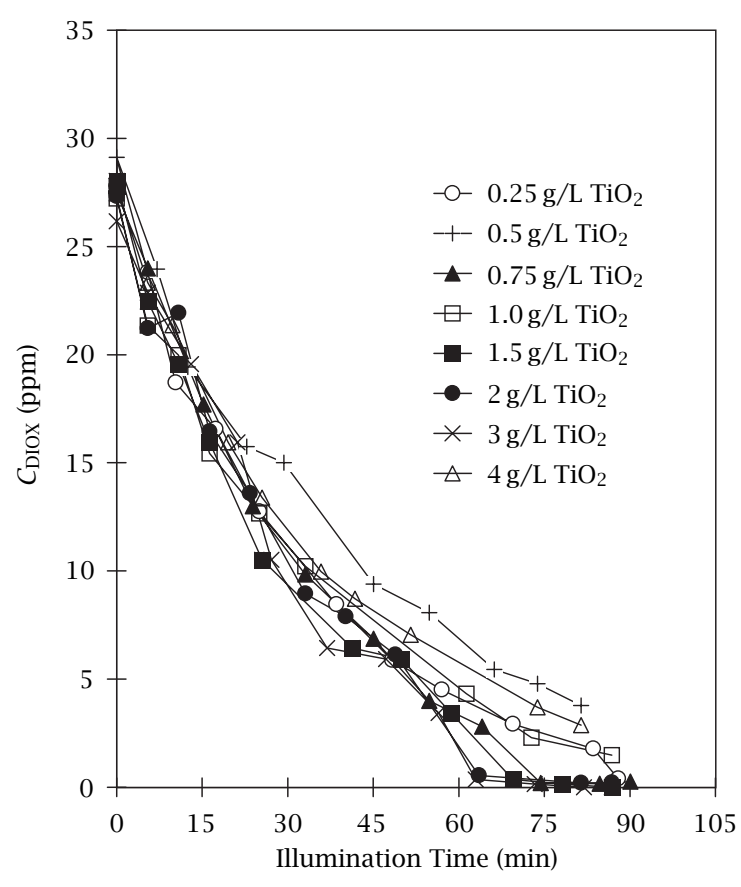

Figure 1. Photocatalytic degradation of 1,4-dioxane in the slurry photoreactor with different Degussa $\mathrm{P} 25 \mathrm{TiO}_{2}$ photocatalyst loadings, $C_{0, D I O X}=27.8 \mathrm{mg} \mathrm{L}^{-1}$. The system was aerated before runs.

for all experimental runs was kept the same as the initial concentration in the Degussa P25 experiments (27.8 $\left.\mathrm{mg} \mathrm{L}^{-1}\right)$.

Figure 2 reveals the concentration-time profile of a series of similar experiments in which photocatalytic degradation of 1,4-dioxane was examined using Hombikat UV 100 photocatalyst at the concentration range of 0.5-7.5 $\mathrm{g} \mathrm{L}^{-1}$. As depicted in Figure 2, at the lowest titanium dioxide loading, i.e., $0.5 \mathrm{~g} \mathrm{~L}^{-1}$, the photocatalytic degradation rate was somewhat slower than those with higher titanium dioxide loadings. It is obvious from this figure that as the loading of titanium dioxide increases, the degradation rate is enhanced. However, the degradation curves are getting closer as the slurry loading increases. At the highest loading, it is difficult to distinguish between the photocatalytic degradation rates. 


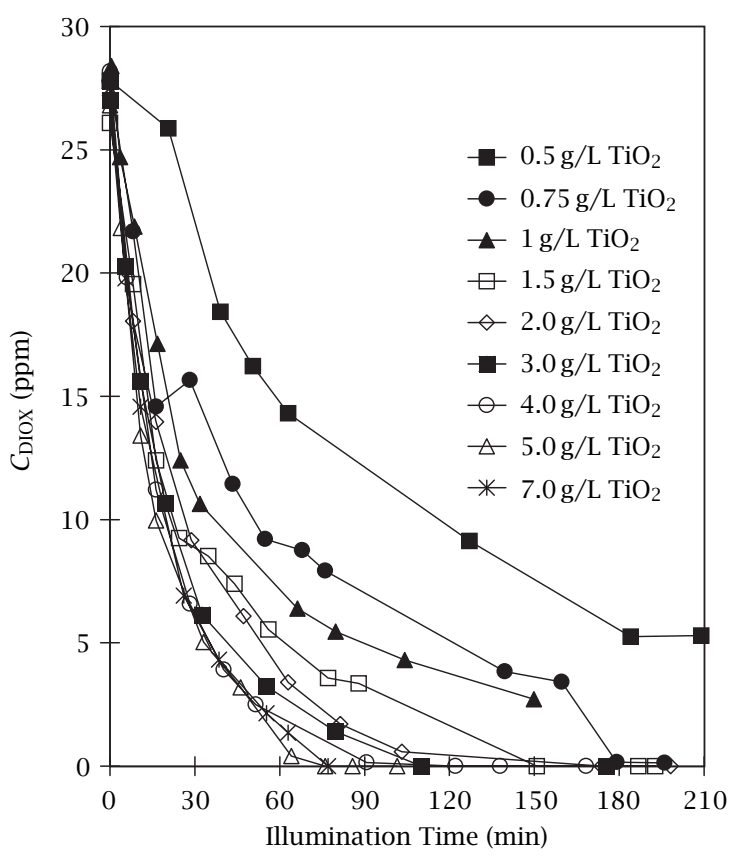

Figure 2. Photocatalytic degradation of 1,4-dioxane in the slurry photoreactor with different Hombikat UV $100 \mathrm{TiO}_{2}$ photocatalyst loading, $C_{0, D I O X}=27.8 \mathrm{mg} \mathrm{L}^{-1}$. The system was aerated before runs.

\subsubsection{Comparison between Degussa P25 and Hombikat UV 100 Titanium Dioxides}

In order to optimize the photocatalyst loading and to compare the results, the method of initial rate was used for each individual run to estimate the initial slope of the concentration-time profiles. Although it was shown that the method of initial rates has some drawbacks such as sensitivity [6], this method is still quick and informative for comparison purposes. The method of initial rates was applied to these experimental runs and the results are depicted in Figure 3.

As illustrated in Figure 3, similar behaviors are seen for the two photocatalysts. As loading increases, the initial rates for both titanium dioxides increase. This increase reached a plateau at a loading of around $1.5 \mathrm{~g} \mathrm{~L}^{-1}$ for Degussa P25 and 3.0-4.0 $\mathrm{gL}^{-1}$ for Hombikat UV 100 titanium dioxide. When the loading of Degussa P25 $\mathrm{TiO}_{2}$ increased to $4.0 \mathrm{~g} \mathrm{~L}^{-1}$, a decrease in the initial rate was observed. This decrease in the initial rate for Degussa $\mathrm{P} 25 \mathrm{TiO}_{2}$ at $4.0 \mathrm{~g} \mathrm{~L}^{-1}$ can be explained easily by the fact that the light cannot penetrate inside the photoreactor zone easily due to the high particle loading. A similar result was observed in UV $100 \mathrm{TiO}_{2}$ at loading of $7.5 \mathrm{~g} \mathrm{~L}^{-1}$.

As depicted in Figure 3, the photoactivity of UV 100 titanium dioxide was almost twice as high as that of Degussa P25 titanium dioxide. Cabrera and co-workers [7] also showed that the photoactivity of UV 100 titanium dioxide is better than that of Degussa P25.

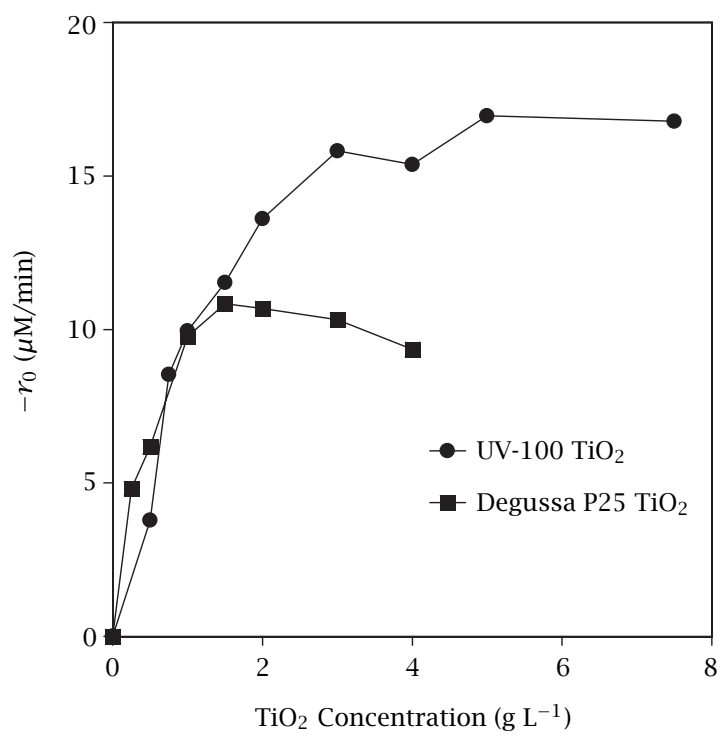

Figure 3. Comparison between initial rates for Hombikat UV 100 and Degussa $\mathrm{P} 25 \mathrm{TiO}_{2}$ catalysts in the slurry photoreactor for different $\mathrm{TiO}_{2}$ loadings, $C_{0, D I O X}=27.8 \mathrm{mg} \mathrm{L}^{-1}$.

The high efficiency for Hombikat UV 100 at high titanium dioxide loadings may be due to its higher surface area and therefore, site availability (see Table 1). In addition, the higher photoactivity of UV 100 photocatalyst can be explained by the fact that it contains $100 \%$ anatase whereas Degussa P25 contains 70\% anatase and $30 \%$ rutile. As the loading of titanium dioxide reaches an optimal level, the efficiency of both photocatalysts remains constant up to a certain loading. Figures 1 and 2 also show that the degradation curves are getting closer.

To better understand the behavior of the system for different photocatalysts, a series of experiments was done to examine the extinction and transmittance of light through the photoreactor. These experiments were performed at a wavelength of $350 \mathrm{~nm}$, that being the wavelength of maximum emission from the UV lamps. Different titanium dioxide slurries were prepared for both photocatalysts in a 500- mL beaker. Immediately prior to the precipitation of the particles in the beaker, the samples were analyzed using a UV spectrophotometer. Extinction and transmittance for different samples were measured at $350 \mathrm{~nm}$ in a $1 \mathrm{~cm}$ cell (Figure 4).

As illustrated in Figure 4, Degussa P25 titanium dioxide absorbs and scatters almost all light going through the photoreactor, even at low concentrations of $\mathrm{TiO}_{2}$. Therefore, the light transmittance is negligible. On the other hand, light extinction in Hombikat UV 100 titanium dioxide rises as the loading of the slurry increases. This increase in extinction continues to a loading of about $2.0 \mathrm{~g} \mathrm{~L}^{-1}$, while the transmittance also drops to zero at the same loading. 


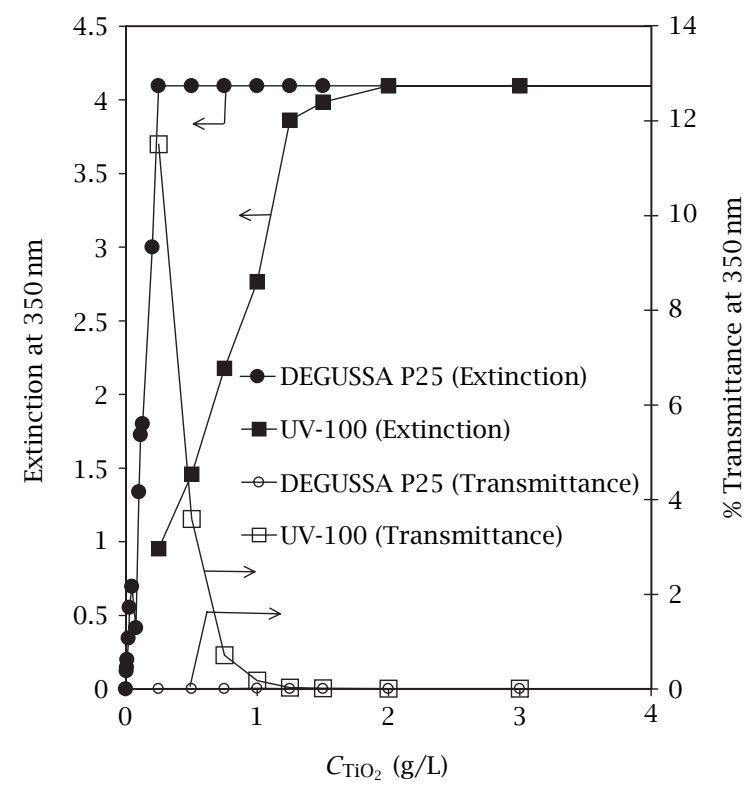

Figure 4. Light extinction and transmittance at $350 \mathrm{~nm}$ for different $\mathrm{TiO}_{2}$ slurry solutions in a $1 \mathrm{~cm}$ cell.

In the case of Hombikat UV 100 photocatalyst, the small particles $(<10 \mathrm{~nm})$ resulted in a blue-shifted absorption spectrum and therefore, higher photocatalyst loading was needed in order to achieve higher particle size by agglomeration and therefore, higher light extinction. A secondary agglomeration with $1 \mu \mathrm{m}$ diameter particles for UV 100 has been reported [8].

Using Figure 4, the extinction coefficients for Degussa P25 and UV 100 titanium dioxides are 16.4 and $3.1 \mathrm{Lg}^{-1} \mathrm{~cm}^{-1}$, respectively. Since the measurements were made in a 1- $\mathrm{cm}$ cell, the extinction relations for both photocatalysts are as follows:

Degussa P25 $\mathrm{TiO}_{2}$ :

$$
E=16.4 l C
$$

UV $100 \mathrm{TiO}_{2}$ :

$$
E=3.1 l C
$$

where $E, l(\mathrm{~cm})$, and $C\left(\mathrm{~g} \mathrm{~L}^{-1}\right)$ are extinction, light path, and the catalyst loading, respectively. The specific extinction coefficients for both photocatalysts $(\beta$ $\left.\left[\mathrm{cm}^{2} \mathrm{~g}^{-1}\right]\right)$, defined as the extinction coefficient per gram of catalyst, were determined to be $4 \times 10^{4}$ and $1 \times$ $10^{4} \mathrm{~cm}^{2} \mathrm{~g}^{-1}$ for Degussa P25 and Hombikat UV 100, respectively. These values are in the same order of magnitude as those found by others [7]. It has been shown that only about $25 \%$ of extinction is contributed to the absorption by the catalysts, whereas the most of it is scattered by the suspended particles [7]. It is conclusive that the specific extinction coefficient for Degussa P25 is 4 times higher than that of Hombikat UV 100 at maximum wavelength emitted by the UV lamps.
The degradation curves do not change significantly over all ranges of catalyst loadings in the case of Degussa P25 (Figure 1). This is because most of the light is scattered through the photoreactor. On the other hand, the degradation curves get steeper as Hombikat UV 100 loading increases (Figure 2). Although the scattering for Hombikat UV 100 is less than that of Degussa P25, the surface area of Hombikat increases as catalyst loading increases.

As the loading of titanium dioxide increases, the transparent layer close to the walls of the photoreactor becomes narrower, i.e., the depth of the light penetration decreases. For example, by using equations (1) and (2), the light paths for the $99 \%$ extinction in the photoreactor for Degussa P25 and UV 100 titanium dioxides with loadings of $5 \mathrm{~g} \mathrm{~L}^{-1}$ are 244 and $1290 \mu \mathrm{m}$, respectively. The laminar boundary layer thickness close to the wall is usually proportional to $\sqrt{D_{e} L / R e}$ [9], where $D_{e}, L$, and $R e$ are the equivalent diameter, the reactor length, and the Reynolds number, respectively. For the Reynolds number of 1513, this value at the length of $0.5 \mathrm{~m}$ is about $4 \mathrm{~mm}$. Therefore, the boundary layer thickness is of the same order of magnitude as the layer in which most of the light is absorbed. This suggests that the reaction rate is becoming mass transfer limited at higher $\mathrm{TiO}_{2}$ loadings, which is why further increases in reaction rate are not observed as the catalyst loading is increased.

With different photoreactor geometries, similar behavior has been observed for both photocatalysts by other researchers [8]. By estimating photonic efficiency, it has been shown that the maximum photonic efficiency obtained by Hombikat UV 100 was about four times higher than that of Degussa P25 titanium dioxide [8]. The same photocatalysts were used in Lindner's research [8] as in this study.

The optimum loading of Degussa P25 was found to be $1.5 \mathrm{~g} \mathrm{~L}^{-1}$ and for Hombikat UV 100 between 3.0-4.0 $\mathrm{g} \mathrm{L}^{-1}$ (see Figure 3). In another study, it was found that the optimum loading for Degussa P25 titanium dioxide was $0.5 \mathrm{~g} \mathrm{~L}^{-1}$ while for Hombikat UV 100 titanium dioxide, it was $5.0 \mathrm{~g} \mathrm{~L}^{-1}$ [8]. This discrepancy could be due to differences in reactor geometries and the model compound employed. In their research, dichloroacetate was used as a model compound.

The total organic carbon (TOC) during the experiments were also measured. The results showed that TOC was reduced slower than the disappearance of the parent compound simply due to the intermediates produced during the reactions. The intermediates during the degradation of 1,4-dioxane were also identified using GC/MS and IC methods. 1,2-Ethanediol, diformate, acetic acid, formic acid, $\beta$-hydroxybutyric acid, and glycolic acid were identified as intermediates of the photocatalytic degradation of 1,4-dioxane. Although, 1,4dioxane-2,3-diol (2,3-dihydroxy-1,4-dioxane) and [1,2ethanediylbis(oxy)]bis[methanol] were not detected, 
it is speculated that they are also 1,4-dioxane intermediates $[4,5]$.

\subsection{Local volumetric rate of energy absorption}

(LVREA). Assuming a line source with parallel plane emission model for this annular photoreactor from both inside and outside of the photoreactor, a simple average volumetric rate of energy absorption may be developed. In this analysis, it is assumed that all light sources outside the photoreactor also act as a line source. For the photoreactor geometry shown in Figure 5, assume $R_{i}$ and $R_{o}$ are the radius of the inner cylinder and the radius of the outer cylinder, respectively. The radiation energy balance for a cylindrical control volume in the region between the inner and outer wall of the photoreactor, i.e., the reactor zone, may be written as follows:

$$
\frac{1}{r} \frac{d}{d r}(r q)=-\mu q
$$

where $q=$ radiant energy flux, [Einstein $m^{-2} s^{-1}$ ]; $r=$ radius, $[\mathrm{cm}] ; \mu=$ extinction coefficient, $\left[\mathrm{cm}^{-1}\right]$.

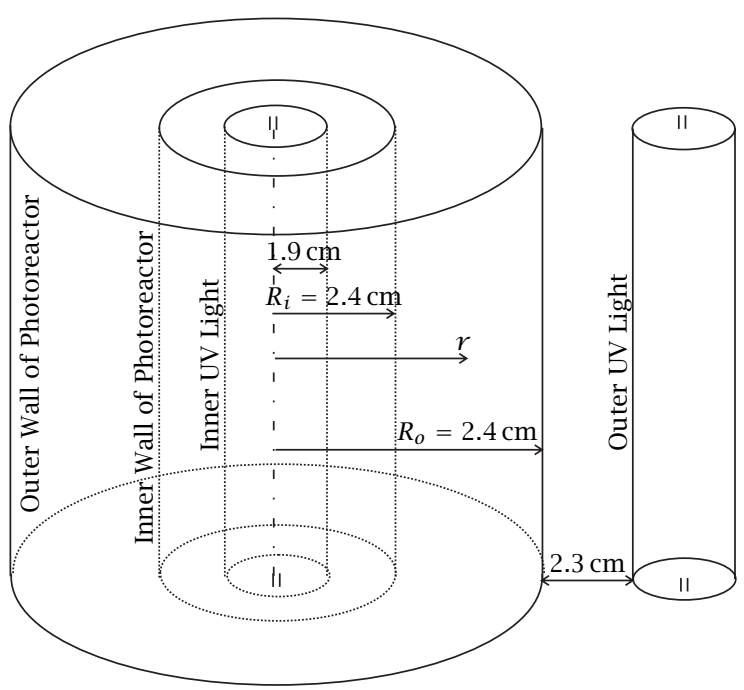

Figure 5. Schematic diagram of the photoreactor geometry and the definitions of the terms for the radiation modeling.

The solution for internal light source with boundary condition $q=q_{w, \text { in }}$ at $r=R_{i}$ is:

$$
q_{1}=q_{w, \text { in }} \frac{R_{i}}{r} e^{-\mu\left(r-R_{i}\right)}
$$

in which $q_{w, \text { in }}$ is the radiant energy flux at the wall of the inner cylinder, [Einstein $\mathrm{m}^{-2} \mathrm{~s}^{-1}$ ].

Similarly, for the outer light source with boundary condition $q=q_{w, \text { out }}$ at $r=R_{o}$ the solution for equation (3) is:

$$
q_{2}=q_{w, o u t} \frac{R_{o}}{r} e^{-\mu\left(R_{o}-r\right)}
$$

in which $q_{w, \text { out }}$ is the radiant energy flux at the wall of the outer cylinder, [Einstein $\mathrm{m}^{-2} \mathrm{~s}^{-1}$ ].

Therefore, the local volumetric rate of energy absorption (LVREA), $A$ [Einstein $\mathrm{m}^{-3} \mathrm{~s}^{-1}$ ], for a control volume inside the photoreactor is:

$$
A=\mu\left(q_{1}+q_{2}\right) .
$$

By substituting equations (4) and (5) into equation (6), the total local volumetric rate of energy absorption is estimated as follows:

$$
A=\mu\left(q_{w, \text { in }} \frac{R_{i}}{r} e^{-\mu\left(r-R_{i}\right)}+q_{w, \text { out }} \frac{R_{o}}{r} e^{-\mu\left(R_{o}-r\right)}\right) .
$$

By assuming $q_{w, \text { in }}=q_{w, \text { out }}=q_{w}$ :

$$
\frac{A}{q_{w}}=\frac{\mu}{r}\left(R_{i} e^{-\mu\left(r-R_{i}\right)}+R_{o} e^{-\mu\left(R_{o}-r\right)}\right) .
$$

The extinction coefficient, $\mu$, could be found from equations (1) and (2). As a result, for Degussa P25, $\mu=16.4$ $C_{\mathrm{TiO}_{2}}$, and for Hombikat UV $100, \mu=3.1 C_{\mathrm{TiO}_{2}}$.

Equation (8) is plotted in Figure 6 for different radii. As illustrated in this figure, it is conclusive that the LVREA for Hombikat UV 100 is higher at higher catalyst concentrations, whereas the LVREA for Degussa P25 is higher at lower catalyst concentrations. Therefore, UV 100 is superior at higher titanium dioxide loading, while Degussa P25 is superior at lower titanium dioxide loading. The results of this modeling is in agreement with the experimental observations shown in Figures 3 and 4 .

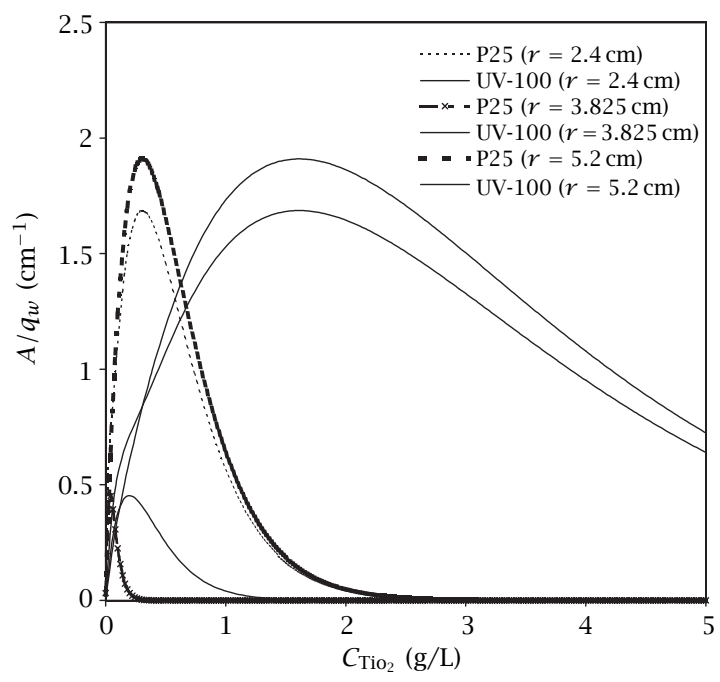

Figure 6. Comparison of LVREA for different radius; $\left(A / q_{w}=\right.$ volumetric rate of absorption/radiant energy flux at the walls). 


\section{CONCLUSION}

Two different photocatalysts, Degussa P25 and Hombikat UV 100, were examined and their photoactivities and optimized loads were compared using 1,4-dioxane. Similar behavior was observed between these two photocatalysts. However, the photoactivity of Degussa P25 was higher at low photocatalyst loadings $\left(\left[\mathrm{TiO}_{2}\right]<1 \mathrm{~g} \mathrm{~L}^{-1}\right)$. At higher photocatalyst loadings $\left.\left(\left[\mathrm{TiO}_{2}\right]>1 \mathrm{gL}^{-1}\right)\right)$, the photoactivity of Hombikat UV 100 was almost twice as high. Mathematical modeling of the radiation within the photoreactor zone also showed similar results, which indicates Hombikat UV 100 was superior at higher titanium dioxide loadings, while Degussa P25 was superior at lower titanium dioxide loadings. The optimum photocatalyst loading for $\mathrm{TiO}_{2}$ was 1.5 and $3.0-4.0 \mathrm{gL}^{-1}$ for Degussa P25 and Hombikat UV 100, respectively. Strictly under the experimental conditions considered, it can be concluded that the Hombikat UV 100 catalyst shows photoactivities higher than the Degussa P25 when the comparison is based on initial degradation rates. Measuring UV absorbance and transmittance at $350 \mathrm{~nm}$ at different $\mathrm{TiO}_{2}$ loadings showed that the system was highly transparent at low Hombikat UV 100 titanium dioxide while it was opaque in the case of Degussa P25 $\mathrm{TiO}_{2}$. In higher titanium dioxide loadings, the system was entirely opaque in the case of both photocatalysts.

\section{ACKNOWLEDGEMENTS}

The support of the Natural Sciences and Engineering Research Council of Canada is gratefully acknowledged.

\section{References}

[1] M. A. Fox and M. T. Dulay, Chem. Rev. 93 (1993), 341.

[2] R. R. Hill, G. E. Jeff, and D. R. Roberts, J. Photochem. Photobiol. A: Chem. 108 (1997), 55.

[3] V. Maurino, P. Calza, C. Minero, E. Pelizzetti, and M. Vincenti, Chemosphere 35 (1997), 2675.

[4] M. Mehrvar, W. A. Anderson, and M. Moo-Young, Int. J. Photoenergy 2 (2000), 67.

[5] M. Mehrvar, W. A. Anderson, and M. Moo-Young, Int. J. Photoenergy 3 (2001), 187.

[6] M. Mehrvar, W. A. Anderson, M. Moo-Young, and P. M. Reilly, Chem. Eng. Sci. 55 (2000), 4885.

[7] M. I. Cabrera, O. M. Alfano, and A. E. Cassano, J. Phys. Chem. 100 (1996), 20043.

[8] M. Lindner, D. W. Bahnemann, B. Hirthe, and W.-D. Griebler, J. Sol. Energy Eng. 119 (1997), 120.

[9] H. Schlichting, Boundary-Layer Theory, McGrawHill, Inc., USA., 6th edition, 1968. 


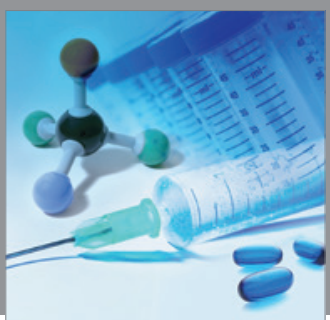

International Journal of

Medicinal Chemistry

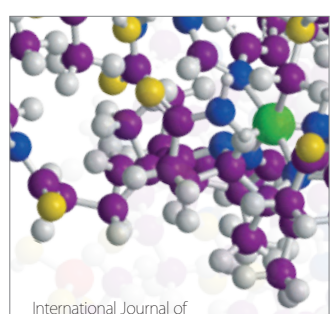

Carbohydrate Chemistry

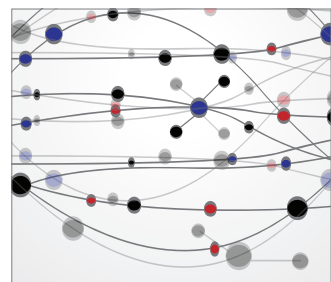

The Scientific World Journal
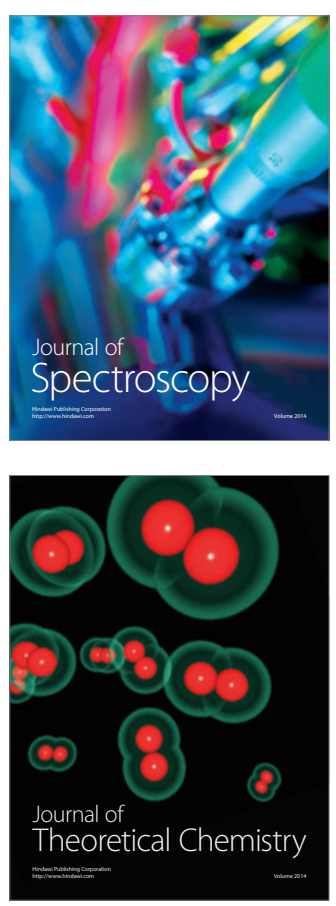
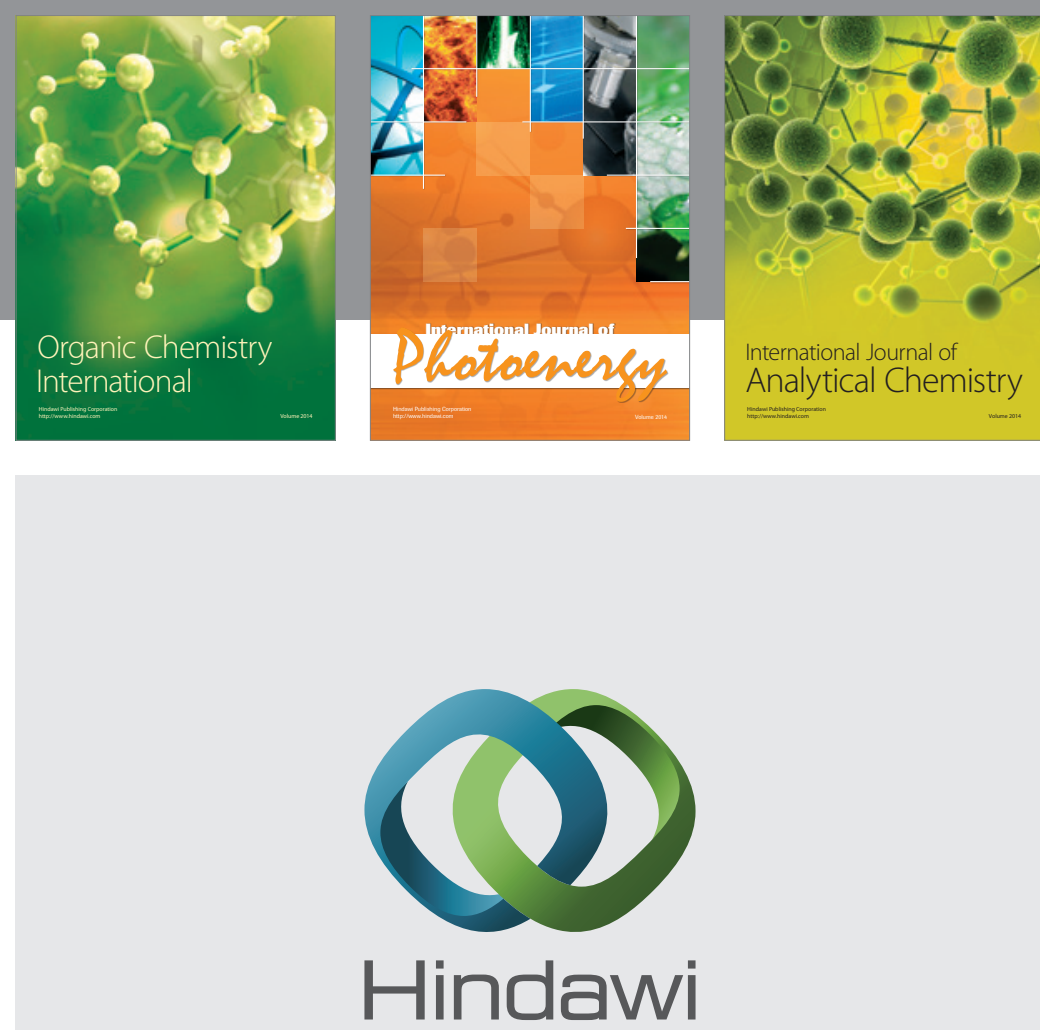

Submit your manuscripts at

http://www.hindawi.com
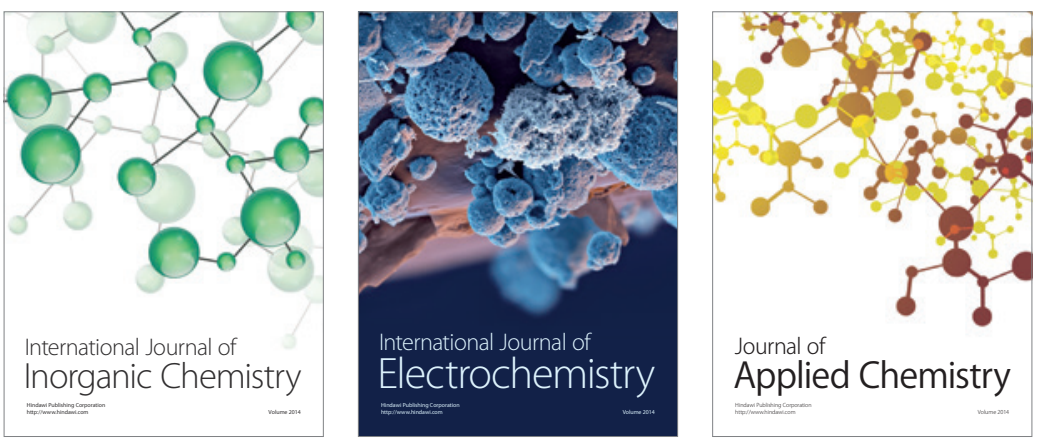

Journal of

Applied Chemistry
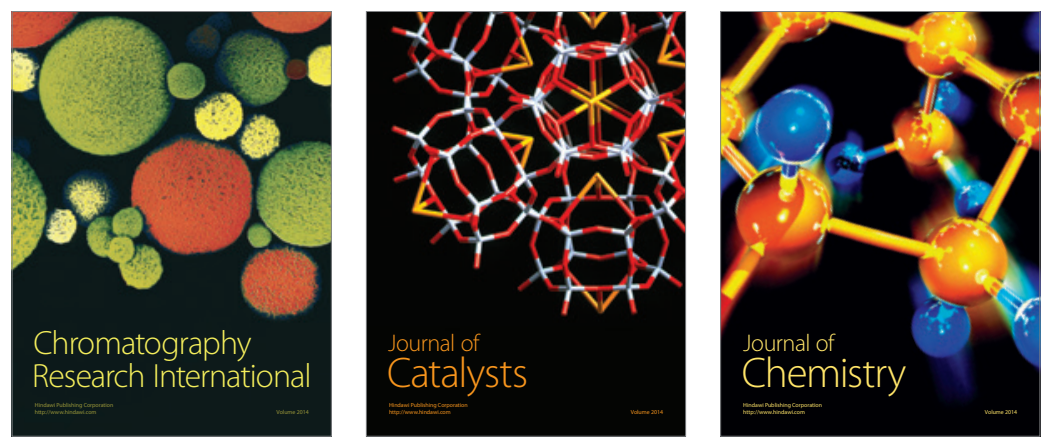
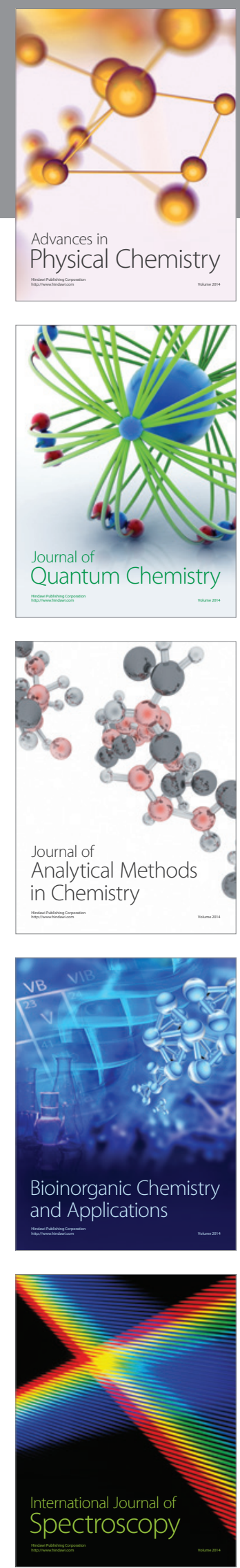